\title{
Effect of Regional Long-Term Care Service Supply on Choice of Care Arrangement in Old Age
}

\author{
Matthias Kuppler ${ }^{1}$ (D) Michael Wagner $^{1}$
}

Received: 5 December 2019 / Accepted: 13 August 2020 / Published online: 21 August 2020

(C) The Author(s) 2020

\begin{abstract}
Depending on their place of residence, older persons have unequal access to long-term care (LTC) services. This article investigates how the county-level supply of inpatient and outpatient LTC services influences individual-level LTC choices of older persons. Administrative data on LTC service supply from the German Care Statistic are combined with representative survey data on the LTC choices of $N=1303$ persons aged $80+$ from the German Federal State North Rhine-Westphalia. Random utility models are applied to model the choice among three care arrangements: receiving inpatient care in an institutional setting (e.g., nursing home), receiving outpatient care in the community, and living in the community without receiving inpatient or outpatient care. The main findings are: Higher inpatient service supply increases the probability that older persons leave the community and enter institutional LTC. Higher outpatient service supply increases the probability that older persons choose to receive outpatient care in the community instead of entering institutional LTC. The results suggest that policy makers must consider the county-level LTC service supply when designing equitable LTC systems that meet the needs of older persons in a costeffective way.
\end{abstract}

Keywords Long-term care $\cdot$ Formal care $\cdot$ Nursing home $\cdot$ Old age $\cdot$ Care choice $\cdot$ Multinomial logistic model

Electronic supplementary material The online version of this article (https://doi.org/10.1007/s12062-02009299-y) contains supplementary material, which is available to authorized users.

Matthias Kuppler

kuppler@wiso.uni-koeln.de

Michael Wagner

mwagner@wiso.uni-koeln.de

1 Institute of Sociology and Social Psychology, University of Cologne, Universitätsstraße 24,

D-50923 Cologne, Germany 


\section{Introduction}

In most Western countries, population ageing and growth of the care-dependent population present challenges to the financing and organization of the long-term care (LTC) system. In Germany, the share of persons aged 65+ is projected to rise from $21.1 \%$ in 2015 to $30.9 \%$ in 2060 (Statistisches Bundesamt 2017), with persons aged $80+$ being one of the fastest growing groups (Huber et al. 2005). As the prevalence of disability increases sharply after age 80 , population ageing is expected to increase the demand for LTC. Therefore, public spending on LTC in Germany is projected to increase from $0.9 \%$ of GDP (2006-2010) to up to 2.1\% of GDP (2060) (Maisonneuve and Martins 2013).

To address these challenges, recent reforms of the German LTC system promoted informal care and formal outpatient LTC services as alternatives to inpatient LTC (Federal Ministry of Health, Germany 2017). Informal and outpatient care are generally more cost-effective than inpatient LTC if care recipients have low to moderate care needs (Wübker et al. 2014). Additionally, informal and outpatient care correspond more closely to the care preferences of older persons who fear that transition to inpatient LTC is associated with reduced quality of life, freedom, and autonomy (Hajek et al. 2018; Lehnert et al. 2018). Only in case of extensive care needs, inpatient care becomes a cost-effective and preferred care arrangement.

Existing research showed that older persons' choices among informal, outpatient, and inpatient care are influenced by the supply of LTC services at their place of residence. Higher supply of inpatient care increases the probability that older persons use inpatient services and decreases the probability that older persons receive informal care in their private households (Pilny and Stroka 2016). Higher public expenditures on outpatient services increase the probability that older persons without informal caregivers remain in the community instead of entering inpatient care (Muramatsu et al. 2007). Conversely, low supply of outpatient care increases the probability that older persons enter inpatient care (Coward et al. 1996; Fischer et al. 2003; Peek et al. 1997).

As LTC choices have important consequences for older persons' quality of life and for public LTC expenditures, these findings are alarming: Low LTC service supply can prevent older persons from receiving their preferred care arrangement. Furthermore, over-supply of inpatient LTC services can lead to unnecessarily high LTC expenditures. To design LTC systems that meet the needs of older persons in a cost-effective way, policy makers need knowledge about how regional disparities in the supply of LTC services influence the LTC choices of older persons. Therefore, the aim of this article is to estimate the effect of the regional LTC service supply on individual-level LTC choices of older persons.

This article makes three contributions to the literature on the LTC choices of older persons: First, longitudinal data from the German Care Statistic (Statistisches Bundesamt 2020a, b) are used to estimate the association between county-level supply and county-level utilization of inpatient and outpatient LTC services. The results allow judging the magnitude of the association between LTC supply and utilization. Second, existing studies have not identified the mechanisms through which LTC supply influences individual-level care choices. To address this gap, this article proposes a LTC choice model that explains how county-level LTC supply affects individual-level LTC choices. Third, the proposed choice model is estimated with data $(N=1303)$ from 
the German research project "Survey on quality of life and subjective well-being of the very old in North Rhine-Westphalia (NRW80+)" (Wagner et al. 2018). NRW80+ is a representative survey of the population aged $80+$ of the German Federal State North Rhine-Westphalia (NRW). We provide estimates for the effect of county-level outpatient and inpatient service supply on individual-level LTC choices. Prior research has either focussed exclusively on the supply of inpatient care (Pilny and Stroka 2016) or used indirect indicators such as state-level spending on outpatient services (Muramatsu et al. 2007).

\section{German Long-Term Care Insurance System}

This section introduces key features of the German LTC insurance (LTCI) system to inform international readers about the specific context in which this study is situated. The German LTCI was introduced in 1995 (Federal Ministry of Health, Germany 2017). Membership in the LTCI is mandatory. The LTCI grants cash benefits for informal caregiving and benefits in kind for formal outpatient and inpatient care services. LTCI benefits are capped and beneficiaries make copayments for costs not covered by the LTCI. For people with low income, a tax-funded social assistance system pays the uncovered costs. The size of LTCI benefits depends on the care dependency of the care recipient. Care dependency denotes physical, cognitive, or other mental impairments that limit the ability to live autonomously for a duration of at least six months. Care dependency is assessed centrally by the Medical Service of the Health Insurances (MDK) with a standardized assessment instrument. Based on the assessment, the MDK assigns care recipients to one of five pre-defined categories (called care grades; in German: Pflegegrade).

Formal LTC services include outpatient and inpatient care services. Outpatient care refers to home-based services provided by qualified nurses. Home-based services provide help in the areas of life that define care dependency and are aimed at promoting care recipients' ability to live in the community rather than in an institutional setting. Inpatient care refers to full- and part-time stationary care provided in an institutional setting (e.g., nursing home) under the permanent presence of a qualified nurse. In contrast to formal LTC provided by qualified health personnel, informal care is provided by non-professional caregivers like spouses, children, and other relatives. In this article, the term care infrastructure is used to refer to the supply of outpatient and inpatient LTC services in a specific geographic region. Care arrangements denote the specific mix of outpatient, inpatient, and informal care received by a care dependent person.

\section{Regional Supply and Utilization of Long-Term Care Services}

This section establishes the explanandum of the article more clearly by describing the association between regional LTC service supply and utilization rates. The German Care Statistic was used to obtain data on LTC supply and utilization on the level of counties (in German: Landkreise, kreisfreie Städe; for a description of the data, see 
"Data and Measures" section). Data is available for $N=375$ counties that where observed every two years from 2003 to 2017.

The supply of LTC services is captured by two indicators: The supply of outpatient care is measured as the number of employees of outpatient care providers per 100 care dependents in a county. The supply of inpatient care is captured by the number of available full-time nursing home $(\mathrm{NH})$ beds per 100 care dependents in a county. Care dependents are persons with officially certified care needs who have been assigned a care grade. In 2017, the supply of outpatient care ranged from 5.1 to 30.5 employees per 100 care dependents. The supply of inpatient care ranged from 11.4 to $53.3 \mathrm{NH}$ beds per 100 care dependents.

Service utilization is captured by two indicators: Utilization of outpatient care is measured as the number of care dependents receiving outpatient care per 100 care dependents in a county. Utilization of inpatient care is captured by the number of care dependents receiving institutional LTC in NHs per 100 care dependents in a county. In 2017, the share of care dependent persons who used outpatient LTC services varied from $12.8 \%$ to $44.4 \%$. The share of care dependent persons who used inpatient LTC services ranged from $11.1 \%$ to $43.3 \%$.

Figure 1 shows the results of a linear fixed-effects regression estimating the effect of the LTC service supply on rates of service utilization with county-level data from the German Care Statistic for the years 2003 to 2017 (see also Table 3 in the Appendix). The panels of Fig. 1 depict conditional effect plots for the supply of outpatient and
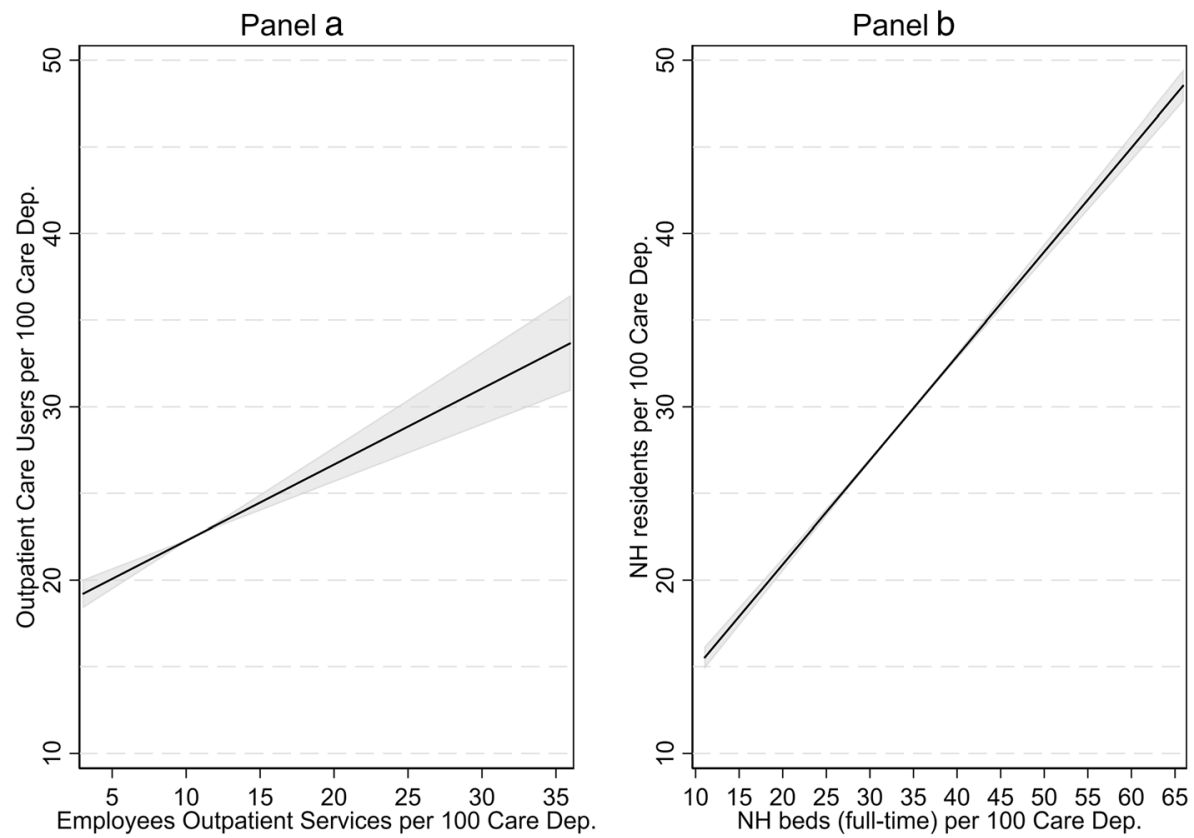

Fig. 1 Effect of LTC supply on utilization of outpatient and inpatient LTC services (adjusted predictions with 95\% confidence intervals). Notes: Results from linear fixed-effects regression models. Models adjust for share of people aged 65+ in county, share of care dependents in county, and year of data collection. Data: German Care Statistic (2003-2017), $N=375$. See the Appendix for a discussion of the statistical model 
inpatient care, respectively. The conditional effect plots show the predicted LTC service utilization over the observed range of LTC service supply.

Higher supply of outpatient care is associated with higher utilization of outpatient services (Panel A): At the lowest observed value of outpatient supply, 19.3 per 100 care dependents receive outpatient care. At the highest observed value, 33.7 per 100 care dependents receive outpatient care. Panel B shows a strong positive effect of inpatient care supply on the utilization of inpatient care: At the lowest observed value of NH bed supply, 15.7 per 100 care dependents receive LTC in NHs. At the highest observed value, 48.6 per 100 care dependents receive LTC in NHs.

In sum, results from the German Care Statistic document a notable association between the care infrastructure and rates of LTC service utilization. The next section formulates a LTC choice model that explains how the LTC supply in the regional care infrastructure affects individual-level care choices. As such, the county-level relation between LTC service supply and utilization is explained as the aggregated result of individual-level care choices.

\section{Long-Term Care Choice Model}

The LTC choice model presented below draws on insights from the Andersen (1995) model of health service utilization, micro-economic models of LTC decision-making (Hoerger et al. 1996; Sarma et al. 2009; Sarma and Simpson 2007), and research on LTC preferences of older persons (Lehnert et al. 2018). According to the Andersen model, utilization of health services is driven by predisposing, enabling, and need factors. Predisposing factors encompass demographic characteristics, health beliefs (attitudes, beliefs, and knowledge about health and health services), and indicators of socio-economic position. Enabling factors refer to personal and community resources that facilitate service use, including the availability of health personnel and facilities as well as the means and knowledge to access them. Need factors capture to the subjectively perceived and professionally assessed health status of a person.

The Andersen model inspired a rich literature on the predictors of inpatient LTC utilization (reviewed in Gaugler et al. 2007; Luppa et al. 2010). However, the model focuses on prediction and does not explicitly specify the mechanisms that produce the statistical relation between the predictors and LTC service utilization. Therefore, it is not possible to clearly state why the predictors exert an effect on LTC service use. A potential remedy is to shift the focus of the model to individual actors and how these actors make care-related decisions. In an actor-centred perspective, statistical relations between variables are explained as the consequence of meaningful decisions of individual actors (Esser 1996). Variables are interpreted as features of the decision situation that affect the decisions of the individual actors. The necessary explanatory mechanisms are provided by a general theory of decision-making.

Micro-economic models of LTC utilization adopt an actor-centred perspective. The models are rooted in rational choice theory (RCT). Commonly, older persons and their families are assumed to choose the LTC service that maximizes their joint family utility. Models differ with respect to the arguments of the family utility function. However, the models generally assume that families derive utility from a good health status of the care recipient and from consumption of other (unspecified) commodities. 
Family production functions specify how the health of the care recipient is produced. Typically, the production functions specify that health depends on investments (e.g., of time and income) into informal and formal care services. The production of health is subject to budget constraints. Families have a fixed amount of time and financial resources to meet the costs of providing informal and formal care. Consequently, families face multiple trade-offs: Every hour that family members spend on informal care reduces the time available for paid labour. Every expense for formal care reduces the income available for consumption of other commodities.

The micro-economic models typically make rather strong assumptions about the rationality of the actors. Actors are assumed to maximize their objective utility. As such, actors have perfect knowledge about their decision situation and consider only objective-material restrictions as part of their budget constraints. Moreover, the preferences of all actors are assumed to be uniform and stable over time. Interindividual differences in behaviour are only explained by differences in the budget constraints. However, empirical research on care preferences of older persons contradicts these assumptions. Choices among care arrangements are not only driven by objective and material restrictions. Actors also consider non-monetary and idealistic factors such as the anticipated personal stress and family strain associated with a care arrangement (Keysor et al. 1999). Moreover, care preferences are not uniform. Preferences are shaped by attitudes towards institutional LTC, cultural values towards care in general, and the personal valuation of autonomy and independence (Min 2005; Werner and Segel-Karpas 2016).

In the present study, the wide version of RCT (Opp 1999) serves as the conceptual basis of the LTC choice model. The wide version does not restrict the kinds of preferences and constraints that guide actors' decisions. The constraints and preferences can be objective and tangible but also subjective and intangible in nature. Furthermore, preferences are not necessarily uniform and stable. Interindividual differences in behaviour can be caused by differences in preferences and constraints. The wide version of RCT is suitable for the present study because it allows to consider the influence of non-monetary and intangible factors on LTC choices (as suggested by the Andersen model and research on LTC preferences) while retaining the firm actorcentred perspective of micro-economic models. The next section calibrates the wide version of RCT to the specific task of explaining LTC choices by specifying a random utility model (RUM) of LTC choices. Bridge assumptions (Brüderl 2004) are formulated to relate actors' utility function to observable features of the decision situation.

\section{Specification of the Random Utility Model}

A RUM (Train 2009) is specified to estimate the effect of the local care infrastructure on the LTC choices of older persons. Let J define the choice set of care arrangements from which actors can choose. Care arrangements are defined by type of care and place of care. Types of care include: no care, informal care, outpatient care, and inpatient care. Place of care can be either in the community or in an institutional setting. The choice set includes three different care arrangements: living in an institutional setting and receiving inpatient care (IC), living in the community and receiving outpatient care (OC), and living in the community without receiving formal care (WOC). 


$$
J=\{I C, O C, W O C\}
$$

Whether the old person receives informal care is not considered in the classification of care arrangements because the substantive interest of this article lies in the effect of formal LTC service supply on the utilization of formal LTC services. Robustness checks show that the inclusion of informal LTC does not alter the results substantively (see Online-Appendix).

Let $U_{n j}$ be the utility that actor n derives from care arrangement $\mathrm{j} \in \mathrm{J}$. The utility $U_{n j}$ is decomposed into a deterministic part $V_{n j}$ and a random part $\varepsilon_{n j}$ such that $U_{n j}=V_{n j}+$ $\varepsilon_{n j}$. The deterministic part relates the unobserved latent utility to a set of observable factors. Let $V_{n j}=x_{n}^{\prime} \beta_{j}$ be a linear combination of $x_{n}^{\prime}$, a vector containing the observable factors, and parameter vector $\beta_{j}$. The content of $x_{n}^{\prime}$ is discussed below. The random part $\varepsilon_{n j}$ captures factors that affect the utility of care arrangements but that are not included in $V_{n j}$. $\varepsilon_{n j}$ is treated as a random variable.

Actors choose the care arrangement that provides the highest utility. That is, actor $n$ chooses care arrangement $i \in \mathrm{J}$ if and only if

$$
U_{n i}>U_{n j} \forall j \neq i
$$

Given the above definitions, the probability $P_{n i}$ that actor $\mathrm{n}$ chooses care arrangement $\mathrm{i}$ is

$$
\begin{gathered}
P_{n i}=\operatorname{Prob}\left(U_{n i}>U_{n j} \forall j \neq i\right) \\
=\operatorname{Prob}\left(V_{n i}+\varepsilon_{n i}>V_{n j}+\varepsilon_{n j} \forall j \neq i\right)
\end{gathered}
$$

Assuming that each $\varepsilon_{n j}$ is independently and identically distributed extreme value, the probability that actor $n$ chooses care arrangement $i$ is given by (see Train 2009: 38ff)

$$
P_{n i}=\frac{\exp \left(V_{n i}\right)}{\sum_{j=1}^{J} \exp \left(V_{n j}\right)}=\frac{\exp \left(\mathrm{x}_{n}^{\prime} \beta_{i}\right)}{\sum_{j=1}^{J} \exp \left(\mathrm{x}_{n}^{\prime} \beta_{\mathrm{j}}\right)}
$$

This correspondents to the multinomial logistic model (MNLM). To identify the model, level and scale of the utility are normalized by choosing the IC arrangement as the reference category and fixing the variance of the error term to the variance of the logistic distribution. Because the choice probability can be written in a closed-form formula, the model can be estimated directly with the maximum likelihood estimator.

\section{Bridge Assumptions}

Now that the basic choice model is specified, bridge assumptions are formulated to relate actors' utility function to observable features of the decision situation. First: Why should the supply of inpatient and outpatient LTC services in the local care infrastructure affect the utility of care arrangements? The underlying argument is simple: The lower the supply of LTC services, the more difficult it is to gain access to these 
services. More formally, the supply of LTC services acts as an external constraint that influences the monetary and non-monetary personal costs of using formal LTC services. The supply of LTC services in the local care infrastructure influences the personal costs associated with care arrangements via at least two mechanisms: First, low service supply increases waiting times for service access. Older persons are found to have a positive willingness to pay for reducing the time spent waiting for LTC service access (Nieboer et al. 2010). Put differently, higher waiting times are perceived as non-monetary costs associated with a care arrangement. Second, lower service supply increases the risk that the service demand cannot be met. If demand exceeds supply, some older persons will not be able to access the service. Unavailability of services at the preferred place of residence either prohibits service utilization or forces older persons to relocate. Residential relocation is associated with personal costs, including giving up a familiar physical setting, disposing of valued possessions (in case of moving to a smaller apartment), departure from a known community, and separation from local friends (Caro et al. 2012). Hence, the lower the supply of outpatient and inpatient care services, the higher the personal costs of using these LTC services. Indirect support for these arguments comes from studies that document an effect of the care infrastructure on individual-level care choices (Coward et al. 1996; Fischer et al. 2003; Muramatsu et al. 2007; Pilny and Stroka 2016).

Based on these arguments, hypotheses about the effect of LTC service supply on individual-level care choices can be derived. If the personal costs of using LTC services increase as the supply of the corresponding LTC services decreases, then it should be true that: (1) The lower the supply of outpatient care services, the lower the utility of using outpatient care (OC arrangement). (2) The lower the supply of inpatient care services, the lower the utility of using inpatient care (IC arrangement). Given that older persons choose the care arrangement that provides the highest utility, the two following hypotheses can be derived.

H1: Lower supply of outpatient services in the local care infrastructure reduces the probability that older persons choose the OC care arrangement.

$\mathrm{H} 2$ : Lower supply of inpatient services in the local care infrastructure reduces the probability that older persons choose the IC care arrangement.

Existing research further suggests that LTC choices of older persons are highly responsive to care needs (Gaugler et al. 2007; Luppa et al. 2010). Older persons prefer to receive care in the community by informal caregivers (WOC arrangement) if care needs are low. As care needs become more extensive, care preferences shift gradually to formal caregivers (OC arrangement) and institutional LTC (IC arrangement) (Caro et al. 2012; Guo et al. 2015; Keysor et al. 1999; Min 2005; Nieboer et al. 2010; SantosEggimann and Meylan 2017; Werner and Segel-Karpas 2016; Wielink et al. 1997).

Qualitative research on care preferences shows that older persons consider the amount autonomy, privacy, and social participation afforded by care arrangements when making LTC decisions (Boisaubin et al. 2007; de São José et al. 2016; Forbes and Hoffart 1998; Harrefors et al. 2009; Tse 2007). Generally, older persons associate transitions to institutional LTC with reduced autonomy, privacy, and social participation. Accordingly, older persons who value autonomy, privacy, and social participation attach higher utility to care arrangements in the community than to arrangements in institutional settings. Hence, older 
persons who value autonomy, privacy, and social participation are more likely to choose the OC and WOC arrangement instead of the IC arrangement.

LTC choices are also affected by the availability of informal caregivers. Lack of informal caregivers must be compensated by formal outpatient services if the older person wants to remain in the community. Outpatient care is associated with additional (monetary) costs. Hence, the absence of informal caregivers reduces the utility of staying in the community. Accordingly, older persons are less likely to remain in the community (OC and WOC arrangement) if they lack access to informal caregivers (Charles and Sevak 2005; Lo Sasso and Johnson 2002; Van Houtven and Norton 2004). Taken together, the vector $x_{n}^{\prime}$ thus contains the following observable factors:

$$
\begin{aligned}
x_{n}^{\prime}= & \text { (LTC service supply; care needs; attitudes towards autonomy } \\
& , \text { privacy, and social participation; availability of informal caregivers })
\end{aligned}
$$

The factors just reviewed fit nicely into the classification of predictors of health service utilization proposed by Andersen (1995). In the Anderson model, health service utilization is a function of predisposing factors (here: attitudes towards autonomy, privacy, and social participation), enabling factors (here: supply of LTC services, availability of informal caregivers), and factors that capture the need for services (here: care needs). However, Andersen (1995) did not adopt an explicit actor-centred perspective in his model. Hence, the decision model proposed in this article can increase the explanatory content of the Andersen model.

\section{Data and Measures}

Analyses are based on data from the German research project "Survey on quality of life and subjective well-being of the very old in North Rhine-Westphalia (NRW80+)." A description of the research project can be found in Wagner et al. (2018). Data on the care infrastructure on the level of counties are taken from the German Care Statistic (Statistisches Bundesamt 2020a, b).

The sampling frame of NRW80+ includes persons aged 80 years or older (born before August 1st, 1937) who live in the German state North Rhine-Westphalia (NRW). NRW is situated in Western Germany, sharing a border with the Netherlands and Belgium. The sampling frame explicitly includes persons in the community and persons in institutional settings. A representative sample was obtained via a multistage sampling design. At the first stage, 120 sampling points located in 94 communities were defined (communities with a large population aged $80+$ contained more than one sampling point). Per sampling point, 400 addresses were randomly drawn from the resident registers. At the second stage, a disproportional sampling strategy with stratification by age-group (80-84, 85-89, and 90+ years) and sex was used to select a sample of $N=8040$ target persons who were contacted for an interview. The fieldwork period extended from August 2017 to February 2018 and resulted in $N=1863$ completed interviews. The AAPOR response rate is $\mathrm{RR} 1=23.4 \%$.

A response rate of $23.4 \%$ is not unusual in surveys of very old persons. For example, the 2014 wave of the German Ageing Survey (DEAS) achieved a response rate of 
27.1\% (Klaus and Engstler 2017). Furthermore, a low response rate does not necessarily imply low representativeness of the sample. A direct assessment of the representativeness is provided in the selectivity analyses below. The geographical restriction of the sample to one Federal State might limit the generalizability of the results. However, NRW is the Federal State with the largest population (approx. 18 Mio residents in 2018; in comparison, the population of the Netherlands in 2018 was about 17.3 Mio). Moreover, the sampling points are located in a diverse set of rural and urban areas. Thus, there is no strong a priori reason to assume that the results described in this article are specific to NRW.

The sampling frame of the German Care Statistic includes all providers of inpatient and outpatient care that are under contract with the public LTC insurances (in German: Pflegekassen). Because participation is mandatory, the statistic captures the entire population of service providers. Data from the Care Statistic are published biannually from 1999 onwards. The most recent data were collected in 2017. From 2003 onwards, aggregated data on the county-level are made publicly available by the German Federal Statistical Office via the Genesis online database (https://www.regionalstatistik. de/genesis/online). The data used in this study were extracted from tables 12411-0203-4 (age structure), 22411-01-01-4 (care providers), and 22411-02-01-4 (care recipients). All data are published by the Federal Statistical Office under the "Data licence Germany - attribution - Version 2.0" (see http://www.govdata.de/dl-de/by-2-0). Data were accessed on July 13th, 2019.

\section{Sample Selection}

Two sample restrictions were applied to the NRW80+ data. First, respondents who transitioned to institutional LTC in 2003 or earlier were excluded $(n=4)$. For these respondents, it was not possible to obtain data on the care infrastructure for the year before the transition to institutional LTC. Second, some communities did not include persons with a "bedingtem Sperrvermerk" (legal regulation that restricts the use of addresses of persons in institutional settings) in the sampling frame. Per definition, the number of respondents in institutional LTC should be zero in these communities, irrespective of the care infrastructure. Inclusion of respondents from these communities would lead to biased estimates of the care infrastructure effect. Thus, the $n=363$ respondents from these communities were excluded. Finally, cases with missing values on any variable used in the analysis were excluded $(n=193)$. The resulting size of the analysis sample is $N=1303$.

\section{Sample Statistics and Selectivity Analysis}

The sample statistics reported below use design weights to take the disproportional sampling strategy into account. On average, respondents in the weighted analysis sample are 84.8 years old (Min: 79, Max: 102). The weighted sample is composed of $42.9 \%$ male and $57.1 \%$ female respondents. The majority of respondents completed vocational secondary education $(60.0 \%)$. General secondary education was the highest level completed by $24.6 \%$ of the respondents, $15.3 \%$ completed tertiary education. Most respondents are widowed and live without a partner $(45.7 \%)$ or are currently partnered $(47.1 \%)$. The remaining respondents are either divorced/separated $(3.7 \%)$ or 
single $(3.4 \%)$. The majority of respondents has no care grade $(72.5 \%)$. The relative shares of persons with care grade are: grade $1(3.0 \%)$, grade $2(10.4 \%)$, grade $3(9.3 \%)$, grade $4(4.0 \%)$, and grade $5(0.9 \%)$. Finally, $8.2 \%$ currently live in an institutional setting, $13.3 \%$ live in the community and receive outpatient care, and $78.5 \%$ live in the community and do not receive formal care.

Data for NRW for the year 2017 from the Care Statistic and from population projections of the Federal Statistical Office (table 12411-04-02-4-B) are used to gauge the representativeness of the sample. Overall, the age distribution in the sample corresponds closely to the population values. However, the sample underrepresents women $(57.1 \%$ in sample vs $63.2 \%$ in population aged $80+$ ), persons with care grade $(27.5 \%$ in sample vs $37.4 \%$ in population aged $80+)$, and persons in institutional settings $(8.2 \%$ in sample vs $10.3 \%$ in population aged $80+$ ). In contrast, persons who receive outpatient care are overrepresented (13.3\% in sample vs $10.2 \%$ in population aged $80+$ ). Overall, the selectivity analyses indicate that the sample is positively selected for respondents with lower care needs. However, the analysis sample contains enough cases of the underrepresented groups to make the multivariate analysis worthwhile. Moreover, robustness checks suggest that care infrastructure effects do not vary by sex. The effects generally point in the same direction for persons with and without higher care needs (indicated by dementia and certified care dependency). In fact, the care choices of persons with higher care needs seem to be more responsive to the LTC supply in the care infrastructure. Thus, if anything, the underrepresentation of persons with higher care needs reduced the size of the infrastructure effects.

\section{Measures}

Table 1 provides descriptive statistics for all variables by care arrangement. Information on the variables not discussed in this section is presented in Table 4 (Appendix).

Care Arrangements The set of care arrangements includes living in an institutional setting and receiving inpatient care (IC), living in the community and receiving outpatient care (OC), and living in the community without receiving formal care (WOC). Three sources of information are used to identify respondents' care arrangement: self-reports on current utilization of inpatient care, self-reports on current utilization of outpatient care, and interviewer reports on the type of dwelling in which respondents live. Interviewers differentiated between institutional settings, private (intergenerational) households, and different forms of assisted living facilities. Assisted living facilities refer to arrangements in which the respondents have an own apartment and can access on-site outpatient services whenever they need them.

Respondents are placed in the IC arrangement if they reported receiving inpatient care and/or if interviewers described their dwelling as an institutional setting $(n=126$, $9.7 \%$ ). The OC arrangement is assigned to respondents who receive formal outpatient services and who live in private households or assisted living settings $(n=196,15.0 \%)$. Finally, respondents who reported that they did not receive formal outpatient services and who live in private households or assisted living settings are assigned to the WOC arrangement $(n=981,75.3 \%)$. 
Table 1 Descriptive statistics by care arrangement (unweighted)

\begin{tabular}{|c|c|c|c|c|c|c|}
\hline \multirow[t]{2}{*}{ Variables } & \multicolumn{2}{|l|}{ IC } & \multicolumn{2}{|l|}{$\mathrm{OC}$} & \multicolumn{2}{|l|}{ WOC } \\
\hline & Mean & SD & Mean & SD & Mean & SD \\
\hline Outpatient LTC supply & 11.15 & 3.15 & 11.51 & 2.68 & 11.47 & 3.08 \\
\hline Inpatient LTC supply & 29.85 & 4.94 & 23.63 & 3.21 & 23.29 & 3.32 \\
\hline Population share $65+$ & 20.50 & 1.47 & 21.02 & 1.45 & 20.88 & 1.61 \\
\hline \multicolumn{7}{|l|}{ Care grade } \\
\hline No care grade & 0.11 & 0.32 & 0.14 & 0.35 & 0.86 & 0.34 \\
\hline Care grade 1 & 0.05 & 0.21 & 0.08 & 0.27 & 0.02 & 0.15 \\
\hline Care grade 2 & 0.27 & 0.45 & 0.34 & 0.47 & 0.05 & 0.23 \\
\hline Care grade 3 & 0.25 & 0.44 & 0.31 & 0.46 & 0.04 & 0.20 \\
\hline Care grade 4 & 0.22 & 0.42 & 0.12 & 0.33 & 0.01 & 0.11 \\
\hline Care grade 5 & 0.10 & 0.29 & 0.01 & 0.07 & 0.00 & 0.06 \\
\hline No. of ADL depend. & 4.25 & 2.25 & 3.28 & 1.89 & 0.81 & 1.50 \\
\hline No. of IADL depend. & 5.60 & 1.87 & 4.57 & 1.84 & 1.58 & 1.98 \\
\hline Age & 89.87 & 5.01 & 87.81 & 4.25 & 85.55 & 4.09 \\
\hline \multicolumn{7}{|l|}{ Valuation of } \\
\hline Autonomy & 3.22 & 0.77 & 3.37 & 0.73 & 3.52 & 0.64 \\
\hline Social participation & 3.50 & 1.14 & 3.62 & 0.92 & 3.62 & 0.95 \\
\hline Privacy & 3.45 & 1.07 & 3.73 & 0.82 & 3.70 & 0.83 \\
\hline$\%$ Currently partnered & 0.15 & 0.36 & 0.33 & 0.47 & 0.52 & 0.50 \\
\hline No. of children & 1.90 & 1.52 & 2.09 & 1.33 & 2.05 & 1.35 \\
\hline NW contacts & 2.05 & 1.12 & 2.72 & 1.07 & 2.76 & 1.17 \\
\hline$\%$ Male & 0.27 & 0.45 & 0.44 & 0.50 & 0.55 & 0.50 \\
\hline Observations & \multicolumn{2}{|c|}{$126(9.7 \%)$} & \multicolumn{2}{|c|}{$196(15.0 \%)$} & \multicolumn{2}{|c|}{$981(75.3 \%)$} \\
\hline
\end{tabular}

LTC Service Supply Information about the care infrastructure on the county-level was obtained from the German Care Statistic. The supply of outpatient services is measured as the number of employees of outpatient service providers per 100 care dependents in the county. The supply of inpatient services is measured as the number of available fulltime places in NHs (short: NH beds) per 100 care dependents in the county. On average, outpatient service providers had 11.5 employees per 100 care dependents (Min: 5.0, Max: 24.8). The average number of NH beds was 24.0 per 100 care dependents (Min: 16.7, Max: 41.8). Additionally, the population share of persons aged $65+$ in the county is used to capture the overall demand for formal inpatient and outpatient care in the county. On average, persons aged $65+$ made up $20.9 \%$ of the population in the counties (Min: 16.5\%, Max: 23.8\%).

Optimally, the data would allow to estimate the effect of the care infrastructure at time point $t$ on choices among care arrangements at time point $t+1$. However, the NRW80+ data only permit to determine the exact time point at which respondents entered an institutional LTC setting. The time point at which respondents started to use outpatient services is not recorded in the data. The following assumptions are made to construct the measures of the local care infrastructure: 
1. Older persons who live in the community are assumed to regularly decide anew which care arrangement provides the highest utility. Their current care arrangement (i.e., the arrangement observed in the data) is the result of a relatively recent decision that should be affected by the current care infrastructure. Hence, for respondents who currently live in the community (OC and WOC arrangements), information on the care infrastructure from 2017 (i.e., the year prior to the survey) is used.

2. The decision to enter an institutional LTC setting is assumed to be rather definitive: Only few older persons who enter institutional LTC settings return to the community afterwards. It cannot be assumed that the current residence in an institutional LTC setting is necessarily the result of a recent decision. Current residence in an institutional LTC setting can be the result of a decision made many years ago. Hence, for respondents in institutional LTC settings (IC arrangement), information on the care infrastructure from the year prior to the transition to the institutional setting is used.

\section{Methods}

All analyses were performed with Stata 16.1 (StataCorp 2019) and user-written commands from the SPost13 (Long and Freese 2014), estout (Jann 2007), and coefplot (Jann 2014) packages. The RUM includes all explanatory variables listed in Table 1. County-clustered standard errors are used to account for the fact that respondents are nested within 47 counties. Design weights are not used in the multivariate analyses. Instead, the model controls for the variables used in the construction of the design weights (age and sex). Similar results were obtained with both strategies. The model-based strategy is preferred because it provides more efficient estimates (Kiesl 2019).

The RUM assumes independence from irrelevant alternatives (IIA). That is, the relative probability of choosing between two care arrangements is independent of any additional arrangements in the choice set. For the current model, Hausman and SmallHsiao tests of the IIA assumption (obtained via the SPost13 ado, see Long and Freese 2014) do not provide conclusive evidence. However, the tests have been shown to possess unfavourable statistical properties (Cheng and Long 2007). Hence, interpretation of the effect estimates rests on the implicit assumption that care arrangements are "distinct and weighted independently in the eyes of each decision-maker" (McFadden 1974: 113). We return to this point in the discussion.

\section{Effect of Regional Long-Term Care Supply on Choice of Care Arrangement}

Table 2 and Fig. 2 present the average marginal effects (AMEs) obtained from the RUM. AMEs represent the average instantaneous rate of change in choice probabilities associated with an explanatory variable. AMEs were multiplied by 100 and, thus, can 
be interpreted as the average change in choice probabilities (in \%points) associated with a one-unit increase in the corresponding explanatory variable. The $95 \%$ confidence intervals were transformed accordingly via endpoint transformation. Figure 2 shows the AMEs of LTC supply. The full set of AMEs is presented in Table 2.

The supply of formal LTC services in the care infrastructure influences which care arrangement is chosen by older persons. The following effects are found for the supply of outpatient care: Each additional employee of outpatient care services per 100 care dependents is associated with a $0.58 \%$ points $(95 \% \mathrm{CI}:-1.36,0.20)$ lower probability of choosing the IC arrangement and a $0.66 \%$ point $(95 \% \mathrm{CI}: 0.07,1.26)$ higher probability of choosing the OC arrangement. The choice of the WOC arrangement is not affected by the supply of outpatient services. For the supply of inpatient care, the following effects are found: Each additional NH bed per 100 care dependents is associated with a $1.47 \%$ points higher probability of choosing the IC arrangement (95\% CI: $0.98,1.96)$, a $0.67 \%$ points lower probability of choosing the OC arrangement (95\% CI: -1.15 , -0.18 ), and a $0.81 \%$ points lower probability of choosing the WOC arrangement (95\% CI: $-1.28,-0.33)$.

\section{Robustness Checks}

Robustness checks were performed to test whether the results presented in the previous section depend on the specification of the RUM (see Online-Appendix). First, the choice set of care arrangements was redefined to reflect whether respondents in the OC and WOC arrangement received informal care. The size and direction of the inpatient service supply effect remained stable. The effect of outpatient service supply was slightly attenuated. However, outpatient service supply still exerted the expected positive effect on the probability of choosing outpatient care.

Second, selectivity analyses revealed that, compared to the population, the analysis sample underrepresents women and care dependent persons. Therefore, it was checked whether the reported effects differ substantially by sex, care dependency, and dementia status. The effects of the LTC service supply variables did not vary substantively by sex. However, the effects were somewhat stronger among care dependent persons and persons with dementia. Thus, if anything, the underrepresentation of care dependent persons reduced the size of the infrastructure effects.

\section{Long-Term Care Supply in Neighbouring Counties}

It was tested whether the effects reported in the previous section were driven by the care infrastructure in neighbouring counties (see Online-Appendix). The care infrastructure in neighbouring counties can affect LTC choices via at least two mechanisms: First, respondents who live at the border of their county can benefit from the outpatient service supply in neighbouring counties because the catchment area of these services can span across county borders (border-spanning supply mechanism). This argument does not apply to inpatient LTC as respondents cannot live in one county and access inpatient care in another county. Second, respondents who want to use a specific LTC service may self-select into counties with high supply of the corresponding LTC service if the supply in their original county of residence is insufficient (selection mechanism). To test these two mechanisms, the average inpatient and outpatient service supply in 


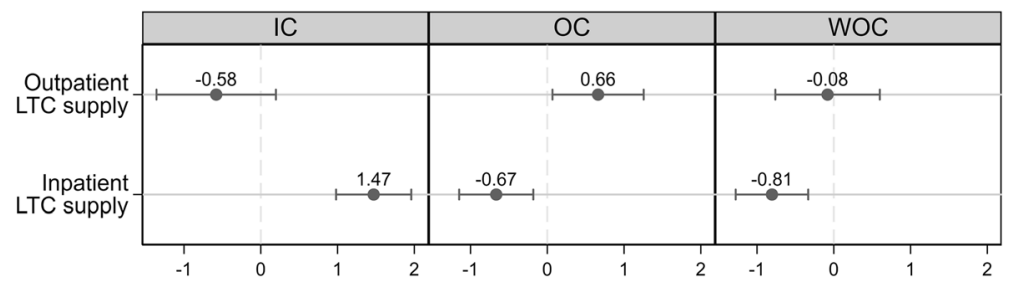

Fig. 2 Effect of LTC supply on choice of care arrangement (average marginal effects with 95\% confidence intervals). Notes: Results from multinomial logistic model based on $N=1303$ observations. The full results of the model are shown in Table 2. AMEs were multiplied by 100 and are interpreted as the average change in choice probabilities (in \% points) associated with a one-unit increase in the corresponding explanatory variable. The $95 \%$ confidence intervals were transformed accordingly via endpoint transformation.

the neighbouring counties was included in the RUM. Counties were considered as neighbours if they share a border. The effect of outpatient service supply (in county of residence) proved to be rather robust and even increased in strength. In contrast, the effect of inpatient service supply (in county of residence) decreased sharply. The selection mechanism seems to hold for outpatient service supply: The lower the supply of outpatient care in neighbouring counties, the higher the probability that respondents in the focal county choose outpatient care. Hence, some respondents seem to have selfselected into their current county in order to access outpatient care. The results for inpatient supply are hard to interpret. Interested readers are referred to the OnlineAppendix.

\section{Discussion}

The results of the empirical analyses show that the supply of inpatient and outpatient services in the care infrastructure influences LTC choices of older persons even after controlling for a set of theoretically meaningful individual-level characteristics. Higher outpatient service supply is related to a higher probability of choosing outpatient care (OC arrangement) and a lower probability of choosing inpatient care (IC arrangement). Higher inpatient service supply is associated with a higher probability of choosing inpatient care (IC arrangement) and a lower probability of choosing outpatient care (OC arrangement) or no formal care at all (WOC arrangement). The results are robust to changes in the specification of the statistical model (see robustness checks). However, future research should further explore the effects of the LTC service supply in neighbouring counties.

The results are in line with existing research on the effect of care infrastructures (Coward et al. 1996; Fischer et al. 2003; Muramatsu et al. 2007; Pilny and Stroka 2016) and with results of the analysis of the German Care Statistic (see Fig. 1). Especially the findings of Pilny and Stroka (2016) lend further support to the plausibility of the results presented in this article. Pilny and Stroka (2016) use nation-wide data from one of Germany's largest health insurances (Techniker Krankenkasse) to estimate the effect of county-level inpatient service supply on choices among care arrangements. Overall, their estimated effects are weaker but point in the same direction. Pilny and Stroka (2016; model specification 2) find that each additional NH bed per 100 care dependents is associated with a $0.4 \%$ points higher probability of choosing inpatient care and a 
Table 2 Estimate of the long-term care choice model (average marginal effects and $95 \%$ confidence intervals)

\begin{tabular}{|c|c|c|c|c|c|c|}
\hline & \multicolumn{2}{|l|}{$\mathrm{IC}$} & \multicolumn{2}{|l|}{$\mathrm{OC}$} & \multicolumn{2}{|l|}{ WOC } \\
\hline & $\begin{array}{l}\text { AME } \\
95 \% C I\end{array}$ & $\mathrm{p}$ Value & $\begin{array}{l}\text { AME } \\
95 \% C I\end{array}$ & $\mathrm{p}$ Value & $\begin{array}{l}\text { AME } \\
95 \% C I\end{array}$ & $\mathrm{p}$ Value \\
\hline \multirow[t]{2}{*}{ Outpatient LTC supply } & -0.58 & 0.14 & 0.66 & 0.03 & -0.08 & 0.82 \\
\hline & -1.36 & 0.20 & 0.07 & 1.26 & -0.76 & 0.60 \\
\hline \multirow[t]{2}{*}{ Inpatient LTC supply } & 1.47 & 0.00 & -0.67 & 0.01 & -0.81 & 0.00 \\
\hline & 0.98 & 1.96 & -1.15 & -0.18 & -1.28 & -0.33 \\
\hline \multirow[t]{2}{*}{ Care grade } & 1.70 & 0.00 & 5.74 & 0.00 & -7.45 & 0.00 \\
\hline & 0.81 & 2.59 & 4.27 & 7.22 & -8.80 & -6.09 \\
\hline \multirow[t]{2}{*}{ No. ADL depend. } & 0.66 & 0.12 & 0.23 & 0.72 & -0.89 & 0.16 \\
\hline & -0.16 & 1.49 & -1.00 & 1.46 & -2.13 & 0.35 \\
\hline \multirow[t]{2}{*}{ No. IADL depend. } & 0.49 & 0.32 & 1.56 & 0.02 & -2.06 & 0.00 \\
\hline & -0.47 & 1.46 & 0.25 & 2.87 & -3.05 & -1.06 \\
\hline \multirow[t]{2}{*}{ Age } & 0.25 & 0.02 & 0.14 & 0.52 & -0.39 & 0.08 \\
\hline & 0.04 & 0.46 & -0.28 & 0.55 & -0.82 & 0.05 \\
\hline \multicolumn{7}{|l|}{ Valuation of } \\
\hline \multirow[t]{2}{*}{ Autonomy } & -0.53 & 0.35 & 1.10 & 0.36 & -0.57 & 0.61 \\
\hline & -1.62 & 0.57 & -1.24 & 3.44 & -2.78 & 1.63 \\
\hline \multirow[t]{2}{*}{ Social participation } & -0.10 & 0.80 & 0.57 & 0.55 & -0.47 & 0.61 \\
\hline & -0.93 & 0.72 & -1.30 & 2.45 & -2.27 & 1.34 \\
\hline \multirow[t]{2}{*}{ Privacy } & -0.70 & 0.23 & 1.29 & 0.17 & -0.59 & 0.50 \\
\hline & -1.83 & 0.43 & -0.57 & 3.15 & -2.29 & 1.11 \\
\hline \multicolumn{7}{|l|}{ Relationship status } \\
\hline Not partnered & \multicolumn{6}{|c|}{ Reference } \\
\hline \multirow[t]{2}{*}{ Partnered } & -3.44 & 0.01 & -1.64 & 0.28 & 5.07 & 0.00 \\
\hline & -6.04 & -0.84 & -4.62 & 1.34 & 2.18 & 7.97 \\
\hline \multirow[t]{2}{*}{ No. of children } & -0.21 & 0.58 & -0.57 & 0.32 & 0.78 & 0.21 \\
\hline & -0.90 & 0.49 & -1.69 & 0.54 & -0.43 & 1.99 \\
\hline \multirow[t]{2}{*}{ NW contacts } & -1.67 & 0.00 & 0.57 & 0.35 & 1.10 & 0.16 \\
\hline & -2.62 & -0.72 & -0.62 & 1.75 & -0.45 & 2.66 \\
\hline \multirow[t]{2}{*}{ Population share $65+$} & -1.34 & 0.03 & 0.83 & 0.24 & 0.51 & 0.46 \\
\hline & -2.56 & -0.11 & -0.55 & 2.21 & -0.83 & 1.84 \\
\hline \multicolumn{7}{|l|}{ Sex } \\
\hline Female & Referenc & & & & & \\
\hline \multirow[t]{2}{*}{ Male } & -1.70 & 0.14 & -0.95 & 0.58 & 2.65 & 0.11 \\
\hline & -3.95 & 0.55 & -4.34 & 2.43 & -0.63 & 5.94 \\
\hline$N$ & 1303 & & & & & \\
\hline
\end{tabular}

Results from multinomial logistic regression model. AMEs were multiplied by 100 and are interpreted as the average change in choice probabilities (in \% points) associated with a one-unit increase in the corresponding explanatory variable. The $95 \%$ confidence intervals were transformed accordingly via endpoint transformation 
$0.1 \%$ points higher probability of choosing a mix of informal and outpatient care. Each additional $\mathrm{NH}$ bed per 100 care dependents is associated with a $0.002 \%$ points lower probability of choosing outpatient care and a $0.5 \%$ points lower probability of choosing informal care.

No directly comparable estimates for the effect of outpatient service supply exist. However, Muramatsu et al. (2007) show that higher state-level expenditures for outpatient services reduce the probability of choosing inpatient care among older persons who lack informal caregivers. The present article expands these results by showing that outpatient service supply also positively affects the probability of choosing outpatient care.

\section{Appropriateness of the Long-Term Care Choice Model}

The empirical results generally support the proposed LTC choice model. Older persons' care needs and attitudes as well as the availability of informal caregivers affect LTC choices in the expected direction. Considering these findings, it seems justified to relax the rather strong rationality assumptions of micro-economic LTC choice models to obtain a more complete picture of how older persons choose among care arrangements. The robustness checks further suggest that the LTC choices of older persons with higher care needs are more strongly affected by the supply of LTC services. While individual-level demand for LTC services and regional supply of LTC services both have notable main effects on LTC choices, they might also interact in interesting ways that warrant further study.

One can criticize the assumption of the model that LTC choices are the result of a conscious utility-maximizing decision-process. However, LTC choices have important and far-reaching consequences for the quality of life of older persons. Hence, older persons and their families can be expected to invest time and cognitive resources in the decision-process. The different care arrangements have distinct properties and the set of available care arrangements is not too extensive. Furthermore, older persons and their families are entitled to carerelated advisory services and, thus, can be expected to be informed about available care arrangements (Federal Ministry of Health, Germany 2017). Yet, cognitive impairments can limit the ability of older persons to make autonomous choices about their preferred care arrangements. If this is the case, observed care choices cannot be interpreted as the result of a conscious utility-maximizing decision undertaken by the older person. Then, it would be more appropriate to study how relatives and healthcare professionals choose care arrangements for the older person.

The robustness checks provide some evidence that cognitive impairments do not strongly change the effects of the local care infrastructure. This finding suggests that older persons, relatives, and healthcare professionals are similarly affected by the constraints set by the care infrastructure. However, other aspects of the decisionprocess may be more responsive to cognitive impairments of older persons (e.g., Gaugler et al. 2009). Future research can explore whether the proposed choice model needs to be modified in order to explain LTC choices made by relatives or healthcare professionals on behalf of the old person (e.g., by including caregiver burden into the utility function). 


\section{Policy Implications}

Population ageing and growth of the care-dependent population present challenges to the financing and organization of the LTC system. To address these challenges, recent reforms of the German LTC system expanded benefits for home-based care in order to promote informal care and outpatient services as alternatives to inpatient care (Federal Ministry of Health, Germany 2017). The results of this study suggest that interventions on the care infrastructure may constitute an additional viable policy instrument. An increase of outpatient service supply by 10 employees per 100 care dependents is predicted to decrease utilization of inpatient care by $5.8 \%$ points. Conversely, decreasing inpatient service supply by $10 \mathrm{NH}$ beds per 100 care dependents is predicted to decrease utilization of inpatient care by $14.7 \%$ points. Further inspection of predicted probabilities obtained from the RUM suggests that the effect will be much larger in counties that have a moderate inpatient service supply than in counties with a relatively low supply (for more details, see Online-Appendix). However, purposefully reducing the supply of inpatient care runs the risk of depriving older persons and their families of a much-needed source of care. Hence, decreases in inpatient service supply should be compensated by increasing the supply of alternative care services, e.g., outpatient care.

\section{Limitations}

In order to provide a firmer basis for designing LTC policies, future research should address the following limitations of the present article: First, the analyses presented in this article rely on cross-sectional data which raises concerns about the causal ordering of explanatory variables and care choices. We tried to address this problem by linking external data from the German Care Statistic. This allowed us to obtain information about the care infrastructure from the years prior to the care decision. However, the construction of the care infrastructure measures relied on rather strong assumptions about the timing of LTC decisions. Thus, the estimated effects should be interpreted as correlations rather than as causal effects. Future studies could use an event-history calendar (EHC) instrument to collect detailed information about the timing of LTC decisions, especially the decision to use outpatient services. In the EHC, respondents can indicate, on a visual timeline, the month and year at which they started or stopped using a particular LTC service (for a critical review of EHCs, see Brüderl et al. 2017).

Second, future studies should provide additional evidence on the size of the care infrastructure effect. This seems warranted because Pilny and Stroka (2016) find weaker effects of the care infrastructure in their nation-wide data set. Third, the IIA assumption inherent in the multinomial logistic model used in this study implies a pattern of proportional substitution between care arrangements (Train 2009): An increase in the probability of choosing one arrangement (e.g., due to increased supply of the corresponding LTC service) is assumed to reduce the choice probabilities of all other arrangements by the same proportion. For instance, increasing the share of older persons who choose the IC setting by raising the supply of inpatient care is assumed to reduce the share of older persons who choose the OC and WOC setting by the same proportion. Further analysis needs to determine whether proportional substitution is a realistic assumption or whether 
decreases in inpatient service supply are more likely to be substituted by higher reliance of older persons on either outpatient or informal care. Similarly, it should be tested whether proportional substitution is a realistic assumption for the effect of outpatient service supply on LTC choices. Finally, additional analyses have to investigate the cost effectiveness of interventions on the care infrastructure.

\section{Conclusion}

Despite these limitations, this article demonstrates that the local care infrastructure influences individual-level care choices. The county-level relation between care infrastructure and rates of LTC service utilization can be understood as the aggregated result of individual-level care choices. The contribution of this article to the literature on LTC choices is threefold: First, the magnitude of the countylevel association between supply and utilization of LTC services is explored in detail. Second, the article provides additional evidence for the importance of local care infrastructures. The results confirm prior findings on the effect of inpatient service supply and provide, for the first time, direct evidence for the effect of outpatient service supply on LTC choices. Research on LTC choices typically focusses on individual- and family-level predictors (e.g., Luppa et al. 2010). This article and existing studies on care infrastructure effects provide an additional perspective for the explanation of care choices. Third, this article clearly states the causal mechanisms that are assumed to underlie individual care choices, moving beyond the mere prediction of care choices that is prevalent in the sociological and gerontological literature. Taken together, this article adds an additional piece to the puzzle of how older persons choose among care arrangements. A puzzle that needs to be solved in order to design LTC systems that meet the needs of older persons in a cost-effective way.

Acknowledgements The project NRW80+ belongs to the Key Research Area "Aging and Demographic Change" (Speaker: Susanne Zank) of the Cologne Center for Ethics, Rights, Economics, and Social Sciences of health (ceres) which is directed by Christiane Woopen at the University of Cologne. Members of the project board are Christian Rietz, Michael Wagner, Christiane Woopen and Susanne Zank. NRW80+ is funded by the Ministry of Innovation, Science and Research, North Rhine-Westphalia. Open Access funding provided by Projekt DEAL.

\section{Compliance with Ethical Standards}

Conflict of Interest The authors declare that they have no conflict of interest.

Ethical Approval All procedures performed in this study that involve human participants were in accordance with the ethical standards of the institutional research committee (Ethik-Kommission der Medizinischen Fakultät der Universität zu Köln, reference number: 17-169) and with the 1964 Helsinki declaration and its later amendments or comparable ethical standards.

Informed Consent Informed consent was obtained from all individual participants included in the study. 


\section{Appendix}

Table 3 Marginal effects (ME) of LTC supply on care utilization (results from fixed-effects regression, data on county-level)

\begin{tabular}{|c|c|c|c|c|c|c|}
\hline \multicolumn{7}{|c|}{ Inpatient service utilization } \\
\hline Supply & ME & Cluster-Robust SE & $\mathrm{t}$ & $p$ Value & \multicolumn{2}{|c|}{$95 \% \mathrm{CI}$} \\
\hline Outpat. Care & -0.04 & 0.03 & -1.42 & 0.16 & -0.09 & 0.01 \\
\hline Inpat. Care & 0.60 & 0.01 & 41.19 & 0.00 & 0.57 & 0.63 \\
\hline \multicolumn{7}{|c|}{ Controls } \\
\hline 2003 & Reference & & & & & \\
\hline 2005 & -0.24 & 0.10 & -2.39 & 0.02 & -0.44 & -0.04 \\
\hline 2007 & -0.73 & 0.14 & -5.17 & 0.00 & -1.01 & -0.45 \\
\hline 2009 & -0.99 & 0.16 & -6.04 & 0.00 & -1.31 & -0.67 \\
\hline 2011 & -1.12 & 0.17 & -6.58 & 0.00 & -1.46 & -0.79 \\
\hline 2013 & -1.16 & 0.20 & -5.87 & 0.00 & -1.55 & -0.77 \\
\hline 2015 & -1.55 & 0.22 & -7.00 & 0.00 & -1.99 & -1.11 \\
\hline 2017 & -1.60 & 0.26 & -6.10 & 0.00 & -2.12 & -1.09 \\
\hline Populat. $65+$ & 20.85 & 5.22 & 4.00 & 0.00 & 10.59 & 31.10 \\
\hline Care Deps. & -0.01 & 0.00 & -3.93 & 0.00 & -0.02 & -0.01 \\
\hline Constant & 7.70 & 1.22 & 6.30 & 0.00 & 5.30 & 10.11 \\
\hline $\mathrm{N}=375$ & \multicolumn{3}{|c|}{$\mathrm{T}=8$} & \multicolumn{3}{|c|}{$\mathrm{F}(11,374)=632.30$} \\
\hline \multicolumn{7}{|c|}{ Outpatient service utilization } \\
\hline Supply & ME & Cluster-Robust SE & $\mathrm{t}$ & $\mathrm{p}$ Value & \multicolumn{2}{|c|}{$95 \% \mathrm{CI}$} \\
\hline Outpat. Care & 0.44 & 0.06 & 7.94 & 0.00 & 0.33 & 0.55 \\
\hline Inpat. Care & -0.21 & 0.02 & -9.28 & 0.00 & -0.25 & -0.16 \\
\hline \multicolumn{7}{|l|}{ Controls } \\
\hline 2003 & Reference & & & & & \\
\hline 2005 & 0.53 & 0.15 & 3.48 & 0.00 & 0.23 & 0.83 \\
\hline 2007 & 0.42 & 0.24 & 1.77 & 0.08 & -0.05 & 0.89 \\
\hline 2009 & 1.26 & 0.30 & 4.16 & 0.00 & 0.66 & 1.86 \\
\hline 2011 & -0.04 & 0.31 & -0.14 & 0.89 & -0.65 & 0.56 \\
\hline 2013 & -0.16 & 0.36 & -0.43 & 0.67 & -0.87 & 0.56 \\
\hline 2015 & -0.35 & 0.42 & -0.84 & 0.40 & -1.17 & 0.47 \\
\hline 2017 & -1.59 & 0.53 & -3.02 & 0.00 & -2.63 & -0.55 \\
\hline Populat. 65+ & 14.82 & 8.37 & 1.77 & 0.08 & -1.64 & 31.28 \\
\hline Care Deps. & 0.03 & 0.01 & 4.63 & 0.00 & 0.02 & 0.04 \\
\hline Constant & 17.74 & 2.28 & 7.79 & 0.00 & 13.27 & 22.22 \\
\hline $\mathrm{N}=375$ & \multicolumn{3}{|c|}{$\mathrm{T}=8$} & \multicolumn{3}{|c|}{$\mathrm{F}(11,374)=58.68$} \\
\hline
\end{tabular}

Analyses rely on data from the German Care Statistic. Only counties that existed continuously between 2003 and 2017 were included in the analysis sample. Due to 
territorial reforms, $n=26$ counties were excluded. The analysis sample includes $N=$ 375 counties that were observed at eight times points (biannually from 2003 to 2017). Linear fixed effects (FE) models are appropriate for this type of panel data (for a description of the model, see Andreß et al. 2013). FE models only use the variation within counties over time. Time-constant terms (effects of time-constant variables and time-constant error terms) are eliminated from the model. Hence, FE models automatically account for all serial correlation and (unobserved) heterogeneity in time-constant terms.

FE estimation assumes that time-point and county-specific error terms (idiosyncratic errors) are homoskedastic and not serially correlated. Tests of heteroskedasticity (xttest3 command in Stata, see Baum 2000) and serial correlation (xtserial command in Stata, see Drukker 2003) indicated that the models are affected by heteroskedasticity and serial correlation. Thus, cluster robust standard errors were applied.

The outcomes of interest are outpatient and inpatient service utilization rates. Rates of outpatient service use are measured as the number of care dependents receiving outpatient services per 100 care dependents in a county. Rates of inpatient service use are measured as the number of care dependents receiving full-time inpatient services per 100 care dependents in a county. The explanatory variables are outpatient service supply (employees of outpatient service providers per 100 care dependents in a county) and inpatient service supply (available full-time places in institutional LTC settings per 100 care dependents in a county). The models further control for potential time trends by including year-dummies. To control for the overall LTC demand in a county, the share of persons aged $65+$ of the total county population and the number of care dependent persons per 1000 inhabitants aged 65+ in a county were included.

The FE estimates are presented in Table 3. The effects are already discussed in the main text. Overall, the models provide a good fit to the data: $F(11,374)=632.30$ with $p<.001$ for inpatient service utilization and $\mathrm{F}(11,374)=58.68$ with $\mathrm{p}<.001$ for outpatient service utilization. 
Table 4 Variable overview

Variable Definition

Care needs

Care grade Extent to which physical, cognitive, and psychological impairments limit autonomy of daily living, assessed by the Medical Service of the Health Insurance Funds (MDK)

- Range: 0 (no impairments) to 5 (severe impairments)

ADL depend. Number of activities of daily living in which respondent needs help from others

- Activities: self-feeding, dressing, personal hygiene, walking, getting out of bed, showering, reaching toilet in time

- Range: 0 (no dependency) to 7 (dependencies in all activities)

IADL depend. Number of instrumental activities of daily living in which respondent needs help from others

- Activities: using a telephone, moving within the community, shopping groceries, preparing meals, doing household chores, taking medicine, and dealing with financial matters

- Range: 0 (no dependency) to 7 (dependencies in all activities)

Age Age in years since birth

- Range: 79 to 102 years

\section{Valuation of}

Autonomy Question text: How important is it for you to do things your own way?

- Range: 1 (not important at all) to 4 (very important)

Privacy Question text: How important is it for you to have time for yourself?

- Range: 1 (not important at all) to 5 (extremely important)

Social Question text: How important is it for you to spend time with others (relatives, friends) and Participation to carry out joint activities?

- Range: 1 (not important at all) to 5 (extremely important)

\section{Availability of informal caregivers}

Relationship Does respondent currently have a living marital or non-marital partner?

status - Range: 1 (yes) or 0 (no)

No. children Number of children

- Range: 0 (no children) to 9 (nine children)

NW contacts Number of network members to whom the respondent has contact at least once per week - Range: 0 (no NW contacts) to 4 (four NW contacts)

Open Access This article is licensed under a Creative Commons Attribution 4.0 International License, which permits use, sharing, adaptation, distribution and reproduction in any medium or format, as long as you give appropriate credit to the original author(s) and the source, provide a link to the Creative Commons licence, and indicate if changes were made. The images or other third party material in this article are included in the article's Creative Commons licence, unless indicated otherwise in a credit line to the material. If material is not included in the article's Creative Commons licence and your intended use is not permitted by statutory regulation or exceeds the permitted use, you will need to obtain permission directly from the copyright holder. To view a copy of this licence, visit http://creativecommons.org/licenses/by/4.0/.

\section{References}

Andersen, R. M. (1995). Revisiting the behavioral model and access to medical care: Does it matter? Journal of Health and Social Behavior, 36(1), 1-10.

Andreß, H.-J., Golsch, K., \& Schmidt, A. W. (2013). Applied panel data analysis for economic and social surveys. Berlin: Springer Berlin Heidelberg. https://doi.org/10.1007/978-3-642-32914-2. 
Baum, C. F. (2000). XTTEST3: Stata module to compute Modified Wald statistic for groupwise heteroskedasticity. https://ideas.repec.org/c/boc/bocode/s414801.html.

Boisaubin, E. V., Chu, A., \& Catalano, J. M. (2007). Perceptions of Long-term care, autonomy, and dignity, by residents, family and care-givers: The Houston experience. Journal of Medicine and Philosophy, 32(5), 447-464. https://doi.org/10.1080/03605310701626414.

Brüderl, J. (2004). Die Überprüfung von rational-choice Modellen mit Umfragedaten. In A. Diekman \& T. Voss (Eds.), Rational-Choice-Theorie in den Sozialwissenschaften. Anwendungen und Probleme (pp. 165-180). München: R. Oldenbourg Verlag.

Brüderl, J., Castiglioni, L., Ludwig, V., Pforr, K., \& Schmiedeberg, C. (2017). Collecting event history data with a panel survey: Combining an electronic event history calendar and dependent interviewing. Methods, Data, 22. https://doi.org/10.12758/MDA.2016.013.

Caro, F. G., Yee, C., Levien, S., Gottlieb, A. S., Winter, J., McFadden, D. L., \& Ho, T. H. (2012). Choosing among residential options: Results of a vignette experiment. Research on Aging, 34(1), 3-33. https://doi. org/10.1177/0164027511404032.

Charles, K. K., \& Sevak, P. (2005). Can family caregiving substitute for nursing home care? Journal of Health Economics, 24(6), 1174-1190. https://doi.org/10.1016/j.jhealeco.2005.05.001.

Cheng, S., \& Long, J. S. (2007). Testing for IIA in the multinomial Logit model. Sociological Methods \& Research, 35(4), 583-600. https://doi.org/10.1177/0049124106292361.

Coward, R. T., Netzer, J. K., \& Mullens, R. A. (1996). Residential differences in the incidence of nursing home admissions across a six-year period. The Journals of Gerontology Series B: Psychological Sciences and Social Sciences, 51B(5), S258-S267. https://doi.org/10.1093/geronb/51B.5.S258.

de São José, J., Barros, R., Samitca, S., \& Teixeira, A. (2016). Older persons' experiences and perspectives of receiving social care: A systematic review of the qualitative literature. Health \& Social Care in the Community, 24(1), 1-11. https://doi.org/10.1111/hsc.12186.

Drukker, D. M. (2003). Testing for serial correlation in linear panel-data models. The Stata Journal: Promoting communications on statistics and Stata, 3(2), 168-177. https://doi.org/10.1177/1536867 X0300300206.

Esser, H. (1996). What is wrong with 'variable sociology'? European Sociological Review, 12(2), 159-166. https://doi.org/10.1093/oxfordjournals.esr.a018183.

Federal Ministry of Health, Germany. (2017). Peer Review on "Germany's latest reforms of the long-term care system." Brussels: European Commision. https://ec.europa.eu/social/main.jsp?langId= de\&catId=1024\&newsId=9008\&furtherNews=yes.

Fischer, L. R., Green, C. A., Goodman, M. J., Brody, K. K., Aickin, M., Wei, F., Phelps, L. W., \& Leutz, W. (2003). Community-based care and risk of nursing home placement. Medical Care, 41(12), 1407-1416. https://doi.org/10.1097/01.MLR.0000100587.51573.7A.

Forbes, S., \& Hoffart, N. (1998). Elders' decision making regarding the use of Long-term care services: A precarious balance. Qualitative Health Research, 8(6), 736-750. https://doi.org/10.1177 /104973239800800602.

Gaugler, J. E., Duval, S., Anderson, K. A., \& Kane, R. L. (2007). Predicting nursing home admission in the U.S: A meta-analysis. BMC Geriatrics, 7(1). https://doi.org/10.1186/1471-2318-7-13.

Gaugler, J. E., Yu, F., Krichbaum, K., \& Wyman, J. F. (2009). Predictors of nursing home admission for persons with dementia. Medical Care, 47(2), 191-198. https://doi.org/10.1097/MLR.0b013e31818457ce.

Guo, J., Konetzka, R. T., Magett, E., \& Dale, W. (2015). Quantifying Long-term care preferences. Medical Decision Making, 35(1), 106-113. https://doi.org/10.1177/0272989X14551641.

Hajek, A., Lehnert, T., Wegener, A., Riedel-Heller, S. G., \& König, H.-H. (2018). Long-term care preferences among individuals of advanced age in Germany: Results of a population-based study. Gesundheitswesen, 80, 685-692. https://doi.org/10.1055/s-0042-124663.

Harrefors, C., Sävenstedt, S., \& Axelsson, K. (2009). Elderly people's perceptions of how they want to be cared for: An interview study with healthy elderly couples in northern Sweden. Scandinavian Journal of Caring Sciences, 23(2), 353-360. https://doi.org/10.1111/j.1471-6712.2008.00629.x.

Hoerger, T. J., Picone, G. A., \& Sloan, F. A. (1996). Public subsidies, private provision of care and living arrangements of the elderly. The Review of Economics and Statistics, 78(3), 428-440. https://doi. org/10.2307/2109790.

Huber, M., Hennessy, P., Izumi, J., Kim, W., Lundsgaard, J., \& OECD (Eds.). (2005). Long-term care for older people. Paris. https://pdfs.semanticscholar.org/d66d/3e0320a619730fb4e09a2c83f05aa6bc83b6. pdf.

Jann, B. (2007). Making regression tables simplified. The Stata Journal: Promoting Communications on Statistics and Stata, 7(2), 227-244. https://doi.org/10.1177/1536867X0700700207.

Jann, B. (2014). Plotting regression coefficients and other estimates. Stata Journal, 14(4), 708-737. 
Keysor, J. J., Desai, T., \& Mutran, E. J. (1999). Elders' preferences for care setting in short- and Long-term disability scenarios. The Gerontologist, 39(3), 334-344. https://doi.org/10.1093/geront/39.3.334.

Kiesl, H. (2019). Gewichtung. In N. Baur \& J. Blasius (Eds.), Handbuch Methoden der empirischen Sozialforschung (2., vollständig überarbeitete und erweiterte Auflage., pp. 405-412). Wiesbaden: Springer VS.

Klaus, D., \& Engstler, H. (2017). Daten und Methoden des Deutschen Alterssurveys. In K. Mahne, J. K. Wolff, J. Simonson, \& C. Tesch-Römer (Eds.), Altern im Wandel: Zwei Jahrzehnte Deutscher Alterssurvey (DEAS) (pp. 29-46). Wiesbaden: Springer VS.

Lehnert, T., Heuchert, M., Hussain, K., \& König, H.-H. (2018). Stated preferences for long-term care: A literature review. Ageing and Society, 1-41. https://doi.org/10.1017/S0144686X18000314.

Lo Sasso, A. T., \& Johnson, R. W. (2002). Does informal care from adult children reduce nursing home admissions for the elderly? INQUIRY: The Journal of Health Care Organization, Provision, and Financing, 39(3), 279-297. https://doi.org/10.5034/inquiryjinl 39.3.279.

Long, J. S., \& Freese, J. (2014). Regression models for categorical dependent variables using Stata (3rd ed.). College Station: Stata Press Publication, StataCorp LP.

Luppa, M., Luck, T., Weyerer, S., Konig, H.-H., Brahler, E., \& Riedel-Heller, S. G. (2010). Prediction of institutionalization in the elderly. A systematic review. Age and Ageing, 39(1), 31-38. https://doi. org/10.1093/ageing/afp202.

Maisonneuve, C. D. L., \& Martins, J. O. (2013). Public spending on health and long-term care: a new set of projections (no. 6). OECD. https://doi.org/10.1787/5k44t7jwwr9x-en.

McFadden, D. L. (1974). Conditional logit analysis of qualitative choice behavior. In P. Zarembka (Ed.), Frontiers in econometrics (pp. 105-142). New York: Academic Press.

Min, J. W. (2005). Preference for Long-term care arrangement and its correlates for older Korean Americans. Journal of Aging and Health, 17(3), 363-395. https://doi.org/10.1177/0898264305276290.

Muramatsu, N., Yin, H., Campbell, R. T., Hoyem, R. L., Jacob, M. A., \& Ross, C. O. (2007). Risk of nursing home admission among older Americans: Does states' spending on home- and community-based services matter? The Journals of Gerontology Series B: Psychological Sciences and Social Sciences, 62(3), S169S178. https://doi.org/10.1093/geronb/62.3.S169.

Nieboer, A. P., Koolman, X., \& Stolk, E. A. (2010). Preferences for long-term care services: Willingness to pay estimates derived from a discrete choice experiment. Social Science \& Medicine, 70(9), 1317-1325. https://doi.org/10.1016/j.socscimed.2009.12.027.

Opp, K.-D. (1999). Contending conceptions of the theory of rational action. Journal of Theoretical Politics, 11(2), 171-202. https://doi.org/10.1177/0951692899011002002.

Peek, C. W., Coward, R. T., Lee, G. R., \& Zsembik, B. A. (1997). The influence of community context on the preferences of older adults for entering a nursing home. The Gerontologist, 37(4), 533-542. https://doi. org/10.1093/geront/37.4.533.

Pilny, A., \& Stroka, M. A. (2016). Determinants of received long-term care - Individual responses to regional nursing home provisions. Health Care Management Science, 19(4), 326-337. https://doi.org/10.1007 /s10729-015-9333-3.

Santos-Eggimann, B., \& Meylan, L. (2017). Older citizens' opinions on Long-term care options: A vignette survey. Journal of the American Medical Directors Association, 18(4), 326-334. https://doi.org/10.1016 /j.jamda.2016.10.010.

Sarma, S., \& Simpson, W. (2007). A panel multinomial logit analysis of elderly living arrangements: Evidence from aging in Manitoba longitudinal data, Canada. Social Science \& Medicine, 65(12), 2539-2552. https://doi.org/10.1016/j.socscimed.2007.07.012.

Sarma, S., Hawley, G., \& Basu, K. (2009). Transitions in living arrangements of Canadian seniors: Findings from the NPHS longitudinal data. Social Science \& Medicine, 68(6), 1106-1113. https://doi.org/10.1016 j.socscimed.2008.12.046.

StataCorp. (2019). Stata statistical software: Release 16. College Station: StataCorp LLC.

Statistisches Bundesamt. (2017). Bevölkerungsentwicklung bis 2060. Ergebnisse der 13. Koordinierten Bevölkerungsvorausberechnung Aktualisierte Rechnung auf basis 2015. Wiesbaden: Statistisches Bundesamt. https://www.destatis.de/DE/Themen/Gesellschaft Umwelt/Bevoelkerung/Bevoelkerungsvorausberechnung/Publikationen/DownloadsVorausberechnung/bevoelkerung-bundeslaender-2060-aktualisiert-5124207179004.pdf?_blob= publicationFile \&v=3.

Statistisches Bundesamt. (2020a). Qualitätsbericht: Statistik über Pflegeeinrichtungen. Wiesbaden: Statistisches Bundesamt. https://www.destatis.de/DE/Methoden/Qualitaet/Qualitaetsberichte/Gesundheit/pflegeeinrichtungenambulant-stationaer.html. Accessed 23 June 2020. 
Statistisches Bundesamt. (2020b). Qualitätsbericht: Statistik über die Empfänger/-innen von Pflegegeldleistungen. Wiesbaden: Statistisches Bundesamt. https://www.destatis. de/DE/Methoden/Qualitaet/Qualitaetsberichte/Gesundheit/pflegeldleistungen.html. Accessed 23 June 2020.

Train, K. E. (2009). Discrete choice methods with simulation (2nd ed.). Cambridge: Cambridge University Press. https://doi.org/10.1017/CBO9780511805271.

Tse, M. M. Y. (2007). Nursing home placement: Perspectives of community-dwelling older persons. Journal of Clinical Nursing, 16(5), 911-917. https://doi.org/10.1111/j.1365-2702.2006.01833.x.

Van Houtven, C. H., \& Norton, E. C. (2004). Informal care and health care use of older adults. Journal of Health Economics, 23(6), 1159-1180. https://doi.org/10.1016/j.jhealeco.2004.04.008.

Wagner, M., Rietz, C., Kaspar, R., Janhsen, A., Geithner, L., Neise, M., Kinne-Wall, C., Woopen, C., \& Zank, S. (2018). Quality of life of the very old: Survey on quality of life and subjective well-being of the very old in North Rhine-Westphalia (NRW80+). Zeitschrift für Gerontologie und Geriatrie, 51(2), 193-199. https://doi.org/10.1007/s00391-017-1217-3.

Werner, P., \& Segel-Karpas, D. (2016). Factors associated with preferences for institutionalized Care in Elderly Persons: Comparing hypothetical conditions of permanent disability and Alzheimer's disease. Journal of Applied Gerontology, 35(4), 444 464. https://doi.org/10.1177/0733464814546041.

Wielink, G., Huijsman, R., \& McDonnell, J. (1997). Preferences for care: A study of the elders living independently in the Netherlands. Research on Aging, 19(2), 174-198. https://doi.org/10.1177 /0164027597192002.

Wübker, A., Zwakhalen, S. M. G., Challis, D., Suhonen, R., Karlsson, S., Zabalegui, A., Soto, M., Saks, K., \& Sauerland, D. (2014). Costs of care for people with dementia just before and after nursing home placement: Primary data from eight European countries. The European Journal of Health Economics, 16(7), 689-707. https://doi.org/10.1007/s10198-014-0620-6.

Publisher's Note Springer Nature remains neutral with regard to jurisdictional claims in published maps and institutional affiliations. 